\title{
The Challenges of an Unpredictable Fat Romance: A Proposal to Turn the Face-clock Back with Total Aesthetic Recall of the Aging-face, Following an Anticlimax of Gaga Euphoria
}

\author{
Lotha Bona ${ }^{1}$ and Mohammed Zeinalddin ${ }^{2 *}$ \\ ${ }^{1}$ U1Craniofacial Cleft Surgeon, Yemen Global Smiles, Sanaa, Yemen \\ ${ }^{2}$ Craniofacial Orthodontist, Mohammad Orthodontic Center - Senior Lecturer, Oman \\ Dental College, Muscat, Sultanate of Oman \\ *Corresponding Author: Mohammed Zeinalddin, Craniofacial Orthodontist, \\ Mohammad Orthodontic Center - Senior Lecturer, Oman Dental College, Muscat, \\ Sultanate of Oman, Oman
}

Received: November 11, 2020

Published: December 14, 2020

(C) All rights are reserved by Lotha Bona and Mohammed Zeinalddin.

\begin{abstract}
Fat grafting for facial rejuvenation is often followed by significant and unpredictable resorption within the first few months. No one has been able to validate the best technique to ensure long term volumetric retention of fat transfer and results continue to be unpredictable. Fat alone as a filler for facial rejuvenation may not be the best option, and other modalities should be considered in addition for treating the aging face. A combination of well standardized, and evidence-based invasive and non-invasive procedures can effectively reduce the effects of aging.
\end{abstract}

Keywords: Facial Rejuvenation; Facelift; Fat Grafting; Aesthetic Medicine; Skincare; Lasers; Fillers; Face Q; AI

\section{Introduction}

Fat grafting is often followed by significant and unpredictable resorption within the first few months. The initial euphoria is quickly replaced by feelings of angst as the fatgasm deflates itself in an anticlimax of sorts. Not unlike a gaga bad-romance. Irrational as it may seem, a feel-good experience in patient-reported outcomes seems to dictate many aesthetic procedures even if they remain outside the confines of the evidence-based, scientific mind.

The beginning of vintage grease research goes back to the First World War when Moristen published thirty-four cases of facial reconstruction using fat as a filler. He noted an improvement in scarring and skin texture. In the 1990s, liposculpture became a fashionable aesthetic procedure in Paris [1].

Neuber in 1893 was the first to use fat grafts in facial defects caused by osteomyelitis [2]. In 1911, Lexter reported that careful preparation of the recipient site and a careful transfer would give optimal results [3]. In the late 1980s, fat grafting was denounced by many leading surgeons stating the early negative results. Surgeons have come to realize that a fat graft can be a useful procedure if done correctly [4].

From the late eighties till the mid-nineties Dr. Coleman proposed the idea of structural fat grafting using 2-3mm blunt-tipped cannulas. He was able to deliver $1 / 50 \mathrm{ml}$ using a 17 gauge cannula $(0.02 \mathrm{ml})$ during each withdrawal [5]. In 2006, T Ming Lin from Taiwan invented the micro autologous fat transfer gun where he could deliver micro fat particles with each pass of $1 / 240 \mathrm{ml}(0.0041 \mathrm{ml})$ [6]. Reported fat graft retention rates can range from $20-80 \%$ at one year. Although fat is an ideal biocompatible filler from one's reserves, the exact amount needed for filling is mostly arbitrary [7]. Fat cells collected by conventional liposuction may not survive well after they are transplanted because they do not have adequate D3PDH intracellular enzyme activity levels, even though the structure and number of viable fat cells are normal [8]. Stromal vascular 
The Challenges of an Unpredictable Fat Romance: A Proposal to Turn the Face-clock Back with Total Aesthetic Recall of the Aging-face, Following an Anticlimax of Gaga Euphoria

fraction (SVF) and growth factors such as platelet-rich plasma matrix (PRPM) may improve the outcome of fat grafting, but there are no evidence-based studies so far [9]. No one has been able to validate the best technique to ensure long term volumetric retention of fat transfer and results continue to be unpredictable [10]. Fat transfer continues to remain in the realm of qualitative research, and although 3D has been used for volumetric imaging, there is no quantitative evidence of long term survival [11].

Fat alone as a filler for facial rejuvenation may not be the best option, and other modalities should be considered in addition for treating the aging face.

The common signs of an aging face are wrinkles, sagging cheeks, jowls, festoons, eyebrow ptosis, and dyschromia. Patients are made aware of these changes as well as the benefits and limitations of surgical and non-surgical treatments [12].

Several changes affect the aging face and facial rejuvenation is not a single modality treatment but a combination of well standardized, and evidence-based procedures that can effectively reduce the effects of aging. Changes of the facial skeleton, laxity of ligaments that suspend the youthful face, descent of the malar pads of fat and soft tissues, as well as loss of skin clarity and texture due to photo damage necessitate treatment of all components to help achieve a natural and youthful appearance.

Many aesthetic practices focus on collagen stimulation, neuromodulation, and skin renewal using superficial peels, fillers, Botox, microdermabrasion, derma pen, lasers, radiofrequency, and other energy devices which tighten skin and stimulate dermal collagen. Some of the minimally invasive procedures are also advocated as first-line treatments for the face and eyelids [13].

\section{Materials and Methods}

We would like to suggest a simple algorithm for facial rejuvenation based on skin and soft tissue changes, as well as the Fitzpatrick and Glogau skin types [14].

Fitzpatrick (FZ) sun reactive skin types

- $\quad$ Type I white skin, always burns, never tans

- Type 2 white skin, always burns, minimal tan

- $\quad$ Type 3 white skin, burns minimally, tans moderately and gradually
- $\quad$ Type 4 light brown skin, burns minimally, tans well

- $\quad$ Type 5 brown skin, rarely burns, and tans deeply

- $\quad$ Type 6 dark brown/black skin, never burns, tans deeply

Glogau wrinkle score

- $\quad$ Glogau (G) scale (describes photo aging)

- $\quad$ Type I no wrinkles, early photo aging

- $\quad$ Type II wrinkles in motion, early to moderate photo aging

- $\quad$ Type III wrinkles at rest, advanced photo aging

- $\quad$ Type IV only wrinkles, severe photo aging

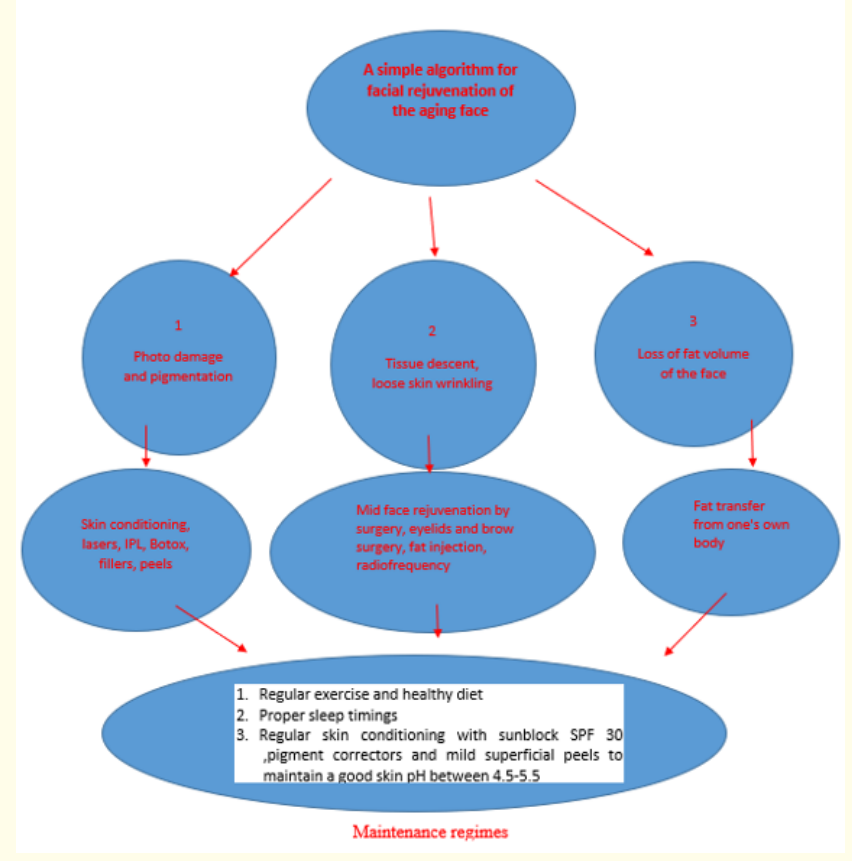

Figure a

We would like to present our take on a gradual, total aesthetic recall (TAR) of the aging face instead of using a single approach. The TAR approach is based on certain criteria in the aging face which can be addressed directly (Table 1) We looked at the most common presentations of the aging face and how steps could be followed to address the treatment issues involved.

Our preference for concomitant filler is fat because it is natural, easily available, and less expensive. 
The Challenges of an Unpredictable Fat Romance: A Proposal to Turn the Face-clock Back with Total Aesthetic Recall of the Aging-face, Following an Anticlimax of Gaga Euphoria

\begin{tabular}{|c|c|c|c|}
\hline $\begin{array}{l}\text { Procedures for age- } \\
\text { related midface changes } \\
\text { and eyes }\end{array}$ & $\begin{array}{l}\text { Procedures for Skin Rejuvenation/pigmenta- } \\
\text { tion }\end{array}$ & $\begin{array}{l}\text { Fat Transfer as part of } \\
\text { the combo treatment }\end{array}$ & $\begin{array}{l}\text { Other options: } \\
\text { Aesthetic smile } \\
\text { dentofacial }\end{array}$ \\
\hline $\begin{array}{l}\text { Surgery remains the gold } \\
\text { standard for } \\
\text { facial rejuvenation, but is } \\
\text { only able to } \\
\text { address skin laxity and } \\
\text { soft tissue. } \\
\text { We use procedures } \\
\text { involving the superficial } \\
\text { musculo aponeurotic } \\
\text { system (SMAS) and sub- } \\
\text { periosteal release(RARE) } \\
\text { [15] }\end{array}$ & $\begin{array}{l}\text { Photo damage causes rhytides, poor skin } \\
\text { texture, and pigmentation problems. Lasers } \\
\text { and IPL target chromophores within tissue: } \\
\text { hemoglobin( } 400-600 \mathrm{~nm}, 577 \mathrm{~nm} \text { being the most } \\
\text { selective), melanin ( } 400 \text { to } 475 \mathrm{~nm} \text { and } 630 \text { to } \\
810 \mathrm{~nm} \text { is the most selective), and water in cells } \\
\text { (ablative lasers) [16]. } \\
\text { Botox and Fillers used properly, can enhance the } \\
\text { aesthetic effects considerably. Botox is useful } \\
\text { for wrinkles and fillers for volume changes. The } \\
\text { goal is not a picture perfect, golden ratio face but } \\
\text { enhancing youthful effects [18] }\end{array}$ & $\begin{array}{l}\text { fat grafting can lead to } \\
\text { Improvement of facial } \\
\text { contours and skin [17]. } \\
\text { Fat Transfer could be } \\
\text { used as part of the } \\
\text { combo treatment }\end{array}$ & $\begin{array}{c}\text { Most patients seek } \\
\text { Cosmetic dentistry } \\
\text { treatment(for } \\
\text { enhancement of the teeth } \\
\text { and smile [19] }\end{array}$ \\
\hline
\end{tabular}

Table 1: Proposing a simple algorithm for rejuvenating the Facial Aesthetic Target Zones [20].

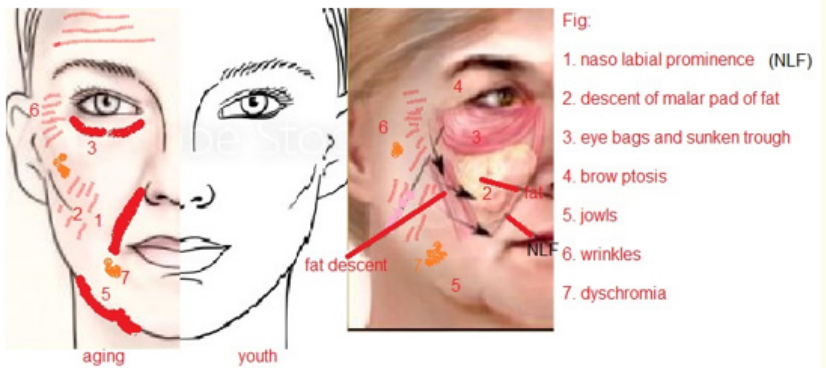

Figure 1: Aging and soft tissue changes as one grows older.

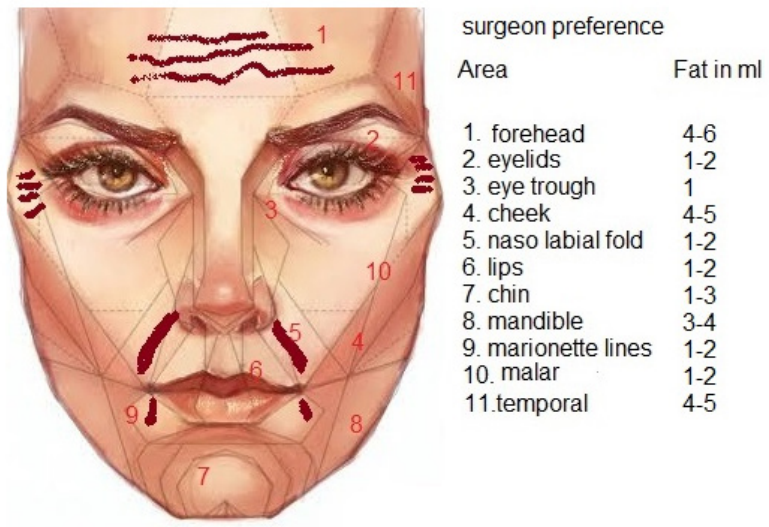

Figure 2: The amount of fat transplanted per facial aesthetic subunit (arbitrary, personal preferences).

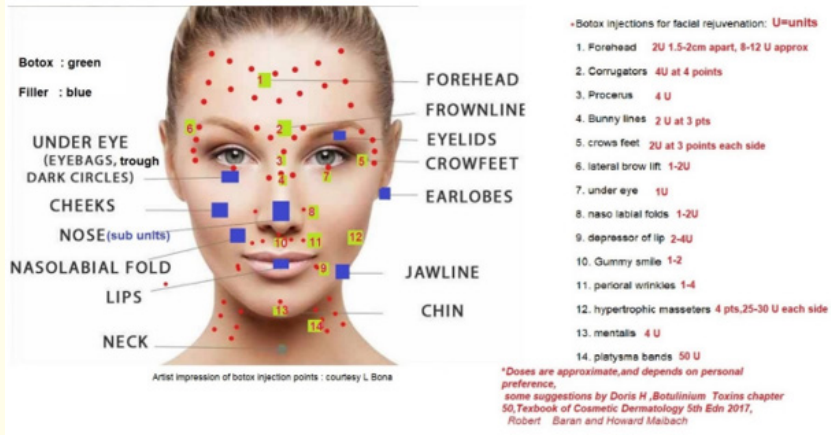

Figure 3: Common points used for Botox rejuvenation of the face; doses are not standardized and depends on operator preference) Courtesy L Bona.

\section{Facelift nuances}

Our preference for surgical facial rejuvenation is to use a minimalist approach on the sub muscular aponeurotic system (SMAS) and sub periosteal, release, and repositioning effect (RARE).

Some nuances of combo face-lifting

- $\quad$ The minimal scar incision avoids the lobes, staying $1 \mathrm{~mm}$ below to prevent a pixie ear.

- Hydro dissect fat plane up to naso labial folds (NLF) -there is no danger because of the nerve arborisation in this region

- Care is taken to prevent post auricular nerve injury

- Staying safe on subcutaneous fat plane

- $\quad$ No platysma entry, stay above this muscle 
The Challenges of an Unpredictable Fat Romance: A Proposal to Turn the Face-clock Back with Total Aesthetic Recall of the Aging-face, Following an Anticlimax of Gaga Euphoria

- $\quad$ Lower limit is the clavicle

- Dissection up to orbicularis oculi margin

- Dissection up to chin, staying on fat plane

- $\quad$ Submental lipo using left index to guide needle (3 hole) 2 or $3 \mathrm{~mm}$

- Middle of neck releasing bands that tether skin

- Lower border of zygomatic arch incision in an inverted L fashion: safe here

- Pull SMAS vertically towards arch

- Lower face dissection is superficial to platysma

- The dissection over masseter is enough for the flap to glide up

- $\quad$ Excess fat is trimmed off

- $\quad$ The anterior and posterior flaps are fixed to marked subcutaneous points

- No displacing earlobe position

- $\quad$ Key sutures are subcutaneous; rest only skin closure needed

- Pretragus is like a full thickness graft taken, in a bevelled fashion

- The pretragus is allowed to sit without tension, as one layer. Only skin sutures needed.

- Key fixation sutures for the lobe; flap is split mid and lateral, fixed without tension

- The blade should "slide" along the fat plane

- $\quad$ Fine face lifting scissors, superficial spreading technique is used

- Under direct vision cut the bands, located in fat and band interfaces

- VECTORS : SMAS is upwards, Skin is Posterior

- The craniofacial author also likes to add a release and repositioning effect (RARE) via the subperiosteal route making small incisions over both canine fossa.

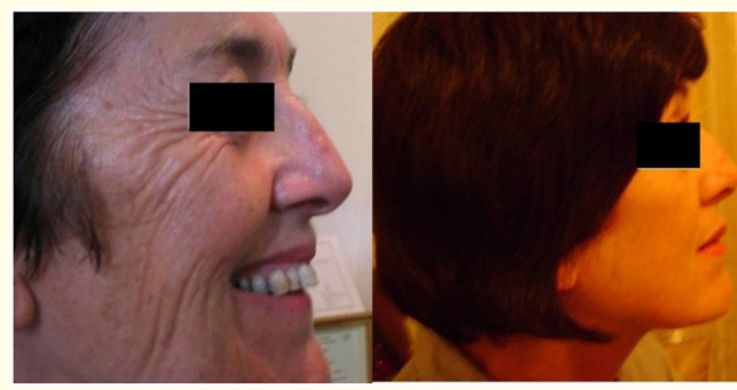

Figure 4: Combo minimal lift and laser resurfacing with upper eyelid rejuvenation 63 -36 lift.

(Courtesy: volunteer @Yemen Global Smiles Lotha B).

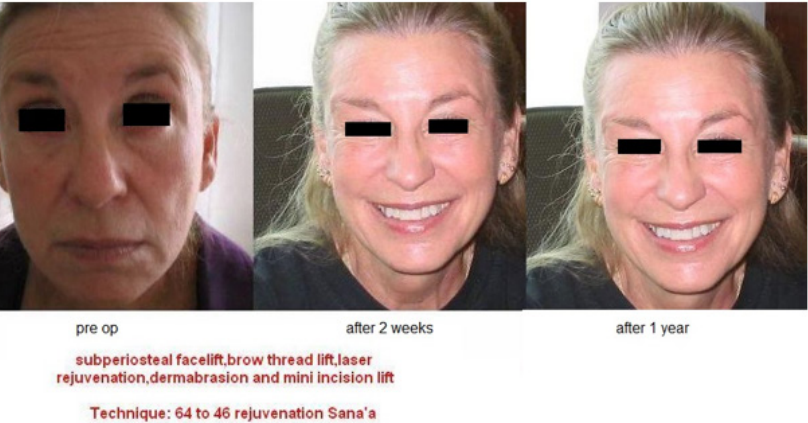

Figure 5: The RARE and minimal incision combo life, thread brow lift, microdermabrasion, and perioral laser.

(Courtesy: volunteer @Yemen Global Smiles Lotha B).

\section{Results and Observations}

A simple approach to regaining facial youth includes non-invasive, minimally invasive, and other treatments. In a total makeover, facial rejuvenation is extended to the earlobes, neck, eyelids, hands, and upper chest areas. Maintenance skincare regimes continue to enhance facial beauty over the long term. The overall effects of combined rejuvenation provide long-lasting benefits as compared to a single procedure alone. Modern facelifts using SMAS and subperiosteal release have mostly replaced traditional lifts. Adjunctive procedures are added using lasers, energy devices, Botox, fillers, and fat. Areas that respond well to Botox include the glabella, crow's feet, gummy smile, masseter, bunny lines, and lateral brow. Fat creates a fuller, youthful look as it fills contour defects. A combination of surgery and aesthetic medicine can give better results than either used alone.

We used a simple software to observe signs of aging in the future (in20years.co).Although simplistic, it could give us some useful ideas about areas commonly affected by the aging process.
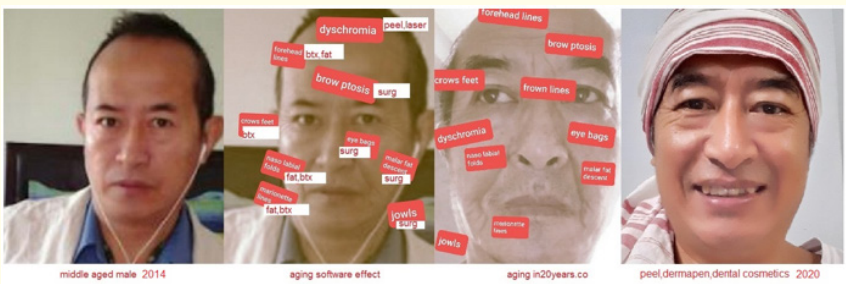

Figure 6: Aging effects using aging software and after dental treatment, derma pen and peel (Courtesy Lotha B). 
The Challenges of an Unpredictable Fat Romance: A Proposal to Turn the Face-clock Back with Total Aesthetic Recall of the Aging-face, Following an Anticlimax of Gaga Euphoria

\section{Discussion and Conclusion}

As one gets older, there will be an inevitable loss of subcutaneous fat, hyaluronic acid, and collagen. The once youthful face with rounded cheeks, raised eyebrows, and almost flawless skin is now replaced by wrinkles, age and sun spots, and loss of facial volume, eye bags, accentuated frown lines, prominent nasolabial folds, and overactive depressor muscles of the lips. The loss of subcutaneous fat is obvious around the orbit, forehead, malar, chin, and mandible. Descent of the malar pad of fat increases the nasolabial fold and lower eye bags prominence. Descent of buccal fat increases the jowls and marionette folds [21].

Principles of fat grafting remain the same despite advances in the delivery of fat ribbons. R Khouri., et al. found that only micro droplets with radii less than $1.6 \mathrm{~mm}$ will completely revascularize and survive fully [22].

Different methods for increasing fat survival have been advocated by surgeons over the years using blunt cannulas, and a $10 \mathrm{cc}$ manual regulation of negative pressure kept at around 2cc [23].

The amount of fat used for facial rejuvenation is not standardized and depends mostly on surgeon preference [24]. Ptosis of the midface components cannot be addressed by fat alone and requires surgical rejuvenation along with fat and other modalities like Botox and lasers.

The superficial musculo aponeurotic system (SMAS) is a mobile structure and can be used to lift the midface and parts of the lower face. Platysma bands that are common in older patients can also be addressed during the face and neck lift to redefine the cervicomental angle [25].

Lin., et al. introduced the concept of micro fat transfer (MAFT) and have shown reliable results in facial rejuvenation. The MAFT gun can be adjusted to deliver micro fat parcels from $1 / 50 \mathrm{ml}$ to $1 / 240 \mathrm{ml}$. It is able to deliver 6 fat-parcel sizes ranging from 0.017 $\mathrm{ml}, 0.011,0.0083,0.0067,0.0056$ and $0.00420 \mathrm{ml} \mathrm{[26].}$

Fat grafting is more successful when transplanted into muscle and fatty tissue subcutaneously. It does not take well on bone, tendon, and fascia [27].
Some surgeons advocate overcorrection, but this leads to a choke-effect and decreases fat cell viability, leading to necrosis and resorption. It is advisable to use minimal amounts for better take of the grafts [28].

Aggressive surgical procedures for facial rejuvenation are no longer the norm, although some proponents of multiple surgical aesthetics do get some very impressive long term results [29]. Facial rejuvenation has mostly shifted towards the minimalist approach using a multi-pronged approach to aesthetics.

As medicine and plastic surgery advances, artificial intelligence (AI) will find tremendous applications in precision plastic surgery recognition soon. On the flip side, artificial intelligence in plastic surgery may provide picture-perfect imaging technologies that are bound to affect patients. The recent foray into plastic surgery using Snapchat imaging has led to instances of Snapchat dysmorphia. Medical groups may also encourage patients to embrace prophylactic aesthetic procedures to enhance private business. AI, however, could help surgeons follow up on patients remotely and check regular progress after surgeries and other treatments [30].

Millions of facial aesthetic procedures continue to be done worldwide but patient-reported outcome instruments (PRO) may not always be reliable or valid. Pusic., et al. proposed a patient satisfaction and face appearance scale using Face $Q$ before and after facial rejuvenation; in their report 94 out of 97 patients who had facelift procedures were satisfied with the treatment. The scale has reliable and valid patient assessments [31].

The good news for aesthetic patients is that there is a wide range of treatments currently available for the aging face. The treatments range from noninvasive to minimally invasive procedures which can benefit the patient. Total Aesthetic Recall of the aging face can reverse many signs of aging using a combination of fat grafting, minimal surgery, peels, lasers, and other devices. That being said, age is only a number and one is only as old or young as one feels.

The results after several interventions and maintenance treatments can enhance the effects of combo-rejuvenation, to the benefit of aging clients. 
The Challenges of an Unpredictable Fat Romance: A Proposal to Turn the Face-clock Back with Total Aesthetic Recall of the Aging-face, Following an Anticlimax of Gaga Euphoria

\section{Bibliography}

1. Nadia Benmoussa MD., et al. "Use of Fat Grafts in Facial Reconstruction on the Wounded Soldiers From the First World War (WWI) by Hippolyte Morestin 1869-1919". Annals of Plastic Surgery 79 (2017): 5.

2. Melvin A Shiffman., et al. "Fat transfer to the face: technique and new concepts". Facial Plastic Surgery Clinics of North America 10 (2002): 191-198.

3. Billing., et al. "Historical review of fat grafting". PRS 83 (1989): 2.

4. R Coleman. "Facial Augmentation With Structural Fat Grafting Sydney”. Clinical Plastic Surgery 33 (2006): 567-577.

5. R Coleman. "Structural Fat Grafting: More Than a Permanent Filler Sydney". Plastic and Reconstructive Surgery 118 (2006).

6. Dr. Lin Tsai-Ming., et al. "Micro-autologous fat transplantation for rejuvenation of the dorsal surface of the aging hand". JPRAS 171 (2018): 573-584.

7. Niechajev I and Sevcuk 0. "Long-term results of fat transplantation: clinical and histologic studies". Plastic and Reconstructive Surgery 94 (1994): 496-506.

8. Lee L Q Pu. "The Viability of Fatty Tissues Within Adipose Aspirates After Conventional Liposuction A Comprehensive Study". Annals of Plastic Surgery 54.3 (2005).

9. R Coleman. "Fat Grafting for Facial Filling and Regeneration Sydney”. Clinical Plastic Surgery 42 (2015): 289-300.

10. Mark J Landau. "Review: Proposed Methods to Improve the Survival of Adipose Tissue in Autologous Fat Grafting". Plastic and Reconstructive Surgery - Global Open 6 (2018): e1870.

11. Matthew R Kaufman. "Autologous Fat Transfer for Facial Recontouring: Is There Science Behind the Art?". Plastic and Reconstructive Surgery 119 (2009): 2287.

12. Samuel M Lam. "The Potential of Autologous Fat Transfer as a Valuable Tool for Cosmetic and Reconstructive Purposes Acknowledged Risks, Limitations, and Benefits". JAMA Facial Plastic Surgery (2018).

13. Jeremy A Brauer., et al. "Laser Skin Resurfacing, Chemical Peels, and Other Cutaneous Treatments of the Brow and Upper Lid". Clinical Plastic Surgery 40 (2013): 91-99.

14. Wendy E. Roberts. "Skin Type Class Systems Old and New". Dermatologic Clinics 27 (2009): 529-533.
15. Barry M Jones. "Volumetric short scar rhytidectomy -indications, technique, and outcomes". Journal of Plastic, Reconstructive and Aesthetic Surgery 61 (2008): 736e743.

16. David A Sieber. "Noninvasive Methods for Lower Facial Rejuvenation". Clinical Plastic Surgery 45 (2018): 571-584.

17. EVAN R RANSOM . "Concurrent structural fat grafting and carbon dioxide laser resurfacing for perioral and lower face rejuvenation". Journal of Cosmetic and Laser Therapy 13 (2011): 6-12.

18. Murad Alam., et al. "Injection techniques in neurotoxins and fillers : planning and basic technique". Journal of American Academy of Dermatology 79 (2018): 407-419.

19. David Sarver. "The Aesthetic Dentofacial Analysis". Clinical Plastic Surgery 34 (2007) 369-394.

20. Andrew A Jacono. "An Algorithmic Approach to Multimodality Midfacial Rejuvenation Using a New Classification System for Midfacial Aging". Clinical Plastic Surgery 42 (2015): 17-32.

21. V Ilankovan. "Anatomy of aging face". British Journal of Oral and Maxillofacial Surgery 52 (2014): 195-202.

22. R Khoury., et al. "Current clinical applications of fat grafting". Plastic and Reconstructive Surgery 140 (2017): 466-486.

23. Giovanni Botti MD. "A Clinical Trial in Facial Fat Grafting: Filtered and Washed versus Centrifuged Fat". Plastic and Reconstructive Surgery 127 (2001): 2464-2473.

24. Shirley Shue., et al. "Fat Injection: A Systematic Review of Injection Volumes by Facial Subunit". Aesthetic Plastic Surgery 42.5 (2017): 1261-1270.

25. D Dasiou-Plakida. "Fat injections for facial rejuvenation". Journal of Cosmetic Dermatology (2004): 119-125.

26. Tsai Ming Lin., et al. "Micro autologous Fat Transplantation for Primary Augmentation Rhinoplasty: Long-Term Monitoring of 198 Asian Patients". Aesthetic Surgery Journal 36.6 (2016): 648-656.

27. Timothy J Martin MD., et al. "Fat grafting in facial rejuvenation". Clinical Plastic Surgery 42 (2015): 219-252.

28. Luigi Clauser MD. “Autologous Fat Transfer for Facial Augmentation: Surgery and Regeneration". Journal of Craniofacial Surgery 30 (2019): 682-685.

29. Robert S Flowers., et al. "Mag-5: a Magnificent Approach to Upper and Midfacial “Magic"'”. Clinical Plastic Surgery 35 (2008): 489-515. 
The Challenges of an Unpredictable Fat Romance: A Proposal to Turn the Face-clock Back with Total Aesthetic Recall of the Aging-face, Following an Anticlimax of Gaga Euphoria

30. You J Kim., et al. "Implementing precision medicine and artificial intelligence in plastic surgery: concepts and future prospects". Plastic and Reconstructive Surgery - Global Open 7 (2019): e2113.

31. Pusic., et al. "Development and Psychometric Evaluation of the FACE-Q Satisfaction with Appearance Scale: A New PatientReported Outcome Instrument for Facial Aesthetics Patients". Clinical Plastic Surgery 40 (2013): 249-260.

\section{Assets from publication with us}

- Prompt Acknowledgement after receiving the article

- Thorough Double blinded peer review

- Rapid Publication

- Issue of Publication Certificate

- High visibility of your Published work

Website: www.actascientific.com/

Submit Article: www.actascientific.com/submission.php

Email us: editor@actascientific.com

Contact us: +919182824667 